\title{
Assessing the Quality of Internet Resources: Challenges and Useful Tools
}

$\mathbf{P}$

atrick was 62 when he was

diagnosed with prostate cancer. In the three months that followed his initial diagnosis, he did everything he could to become an expert on the disease. He started doing his research as soon as he got home from the doctor's office and estimates that he spent seven to eight hours-a-day, seven-daysa-week on the computer until his surgery. As Patrick stated,

There's a world of information out there. I mean, it's unbelievable how much information is available on the Internet about prostate cancer. You've got to be patient and wade through a lot to get to the good information. But if you persevere, you can become as knowledgeable as any lay person can be about this.

Patrick's motivation was to make the best treatment decision that he could in the face of his cancer diagnosis. He didn't think of himself as a self-directed learner but rather as someone who wanted to be well informed. He said, "I want to know everything there is to know about whatever I'm doing or going into ... That's just my way ... I do not like to be blindsided."

Knowles' (1975) defined self-directed learning as "a process in which individuals take the initiative with or without the help of others in diagnosing their learning needs, formulating goals, identifying human and material resources, selecting appropriate learning strategies and evaluating learning outcomes" (p. 18). That is exactly what Patrick did in response to his prostate cancer. Stories like his story are replicated hundreds of thousands of times daily as more and more people turn to the Internet as a major resource in their self-directed learning.

\section{Using the Internet for Self-Directed Learning}

Gray (1999) defines the Internet as a network of computers from all over the world that are connected in such a way that they can communicate with each other and information can be shared. Many people think that the World Wide Web is a synonym for the Internet and the terms are commonly used interchangeably. Technically, however, the Web is a part of the Internet. Its distinguishing feature is its use of hypertext which allows for instant transfer or linkage to related sites. In any case, the Internet has been cited "as one of the most powerful and important self-directed learning tools in existence" (Gray, p. 120).

Use of the Internet and the World Wide Web is increasing rapidly. Determining just how many people are currently making use of this technology is extremely difficult because many are accessing it through school, work, or public libraries and not necessarily through home computers. Kling (1999) estimates that, "In 1995, about 28.8 million people in the United States 16 years and over had access to the Internet at work, school, or home; 16.4 million people used the Internet and 11.5 million of these people use the Web" (p. 58). Those numbers have grown tremendously for experts suggest that access to the Internet in the United States doubles every two years.

Spear and Mocker's (1984) landmark study regarding self-directed learning resources contributes an interesting perspective on the critical nature of the Internet's impact on this process. Their

\section{By Katbleen B. Rager}

Katbleen B. Rager is an assistant professor of Adult Education at the University of Oklahoma where she is responsible for the emphasis in training and development. Her research interests include self-directed learning particularly in the contexts of health care and corporate training, gender, and the self care of the qualitative researcher when conducting emotionally laden studies.

\section{(E-mail:kbrager@ou.edu)}


findings indicated that self-directed learners "tend to select a course from limited alternatives which occur fortuitously within their environment, and which structures their learning projects" (p. 4). They called this concept the "organizing circumstance." Now with the proliferation of the Internet, anyone with a computer, Internet access, and the appropriate skills has the ability to tap into vast resources that are electronically available about any subject. In a sense, it provides everyone that can use it with the same "environment," thereby profoundly impacting the "organizing circumstance." However, as the Internet eliminates geographic location as a factor in accessing abundant resources for its users, it simultaneously increases the importance of skill in distinguishing quality resources from junk.

One of the factors further complicating this issue is the reality that most people learn to use the Internet and the Web on their own, through trial and error (Cahoon, 1998). Few have taken any type of course to develop their skills. Therefore, most have never learned to critically evaluate electronically accessed information and some are not even aware of the need to do so.

However, because there are no safeguards in place controlling what is available on the Internet; credible resources exist side-by-side with those that are not. According to Morrison and Stein (1999), "The World Wide Web (WWW) contains extensive data that is timely and useful, but it also offers propaganda, facts, and charts without dates or references, and opinions from individuals without authoritative knowledge" (p. 317). In addition, among the highly publicized abuses are cases of outright fraud available on the Internet. It is useful both on an individual level and for classroom instruction. It covers issues such as determining the purpose of a Web site, its orientation, the meaning of URLs, and other pertinent topics. To complete the entire program requires about two hours. However, it is possible to select individual modules and therefore to modify the program to address specific needs. The Web site for Internet Detective also includes additional material for teachers and trainers who choose to make use of the tutorial with their students.

A similar resource has been developed at Ohio State University. It is a shorter online tutorial entitled net.TUTOR. This Web site evaluation program can be completed in 15 to 30 minutes and contains links to example sites. It is organized into six modules that cover purpose, author, content, coverage, currency, and recognition.

Both Internet Detective (2001) and net.TUTOR (2001) are excellent electronic resources that can be useful in a variety of settings in raising awareness and in developing skill in determining Internet information quality. They are provided as a public service and, therefore, there is no charge to individuals or to instructors who make use of them.

\section{Five Criteria for Evaluating Web Pages}

However, the same goals can be accomplished through non-technical means. Experts are fairly consistent in suggesting that Web pages be evaluated through the lens of the same five criteria: autbority, accuracy, currency, objectivity, and coverage (Kapoun, 1998). They maintain that the process begins with clarity regarding the purpose of a search. Obviously, one evaluates Web sites differently if the purpose is entertainment versus Patrick's purpose of accessing reliable medical information on which to base decisions regarding his prostate cancer treatment. In Patrick's case, the quality of the information was critical. and criminal activity. Ultimately, it is the user who must accept responsibility for distinguishing fact from fiction on the Internet.

\section{Strategies for Helping Learners Evaluate Internet Resources}

Given these circumstances, the ability to critically evaluate Internet resources should be an area of concern to adult educators in general and to those interested in self-directed learning in particular. Adult education practitioners can and should play a role in focusing on the need to critically evaluate Internet information and in helping adult learners develop the ability to do so.

Fortunately, resources are available to help in developing expertise in this regard. One excellent tool is called Internet Detective (2001). It is a free interactive tutorial that is appropriate for adults and high school students. Internet Detective is a fairly comprehensive program that is
The criterion of authority refers to investigating the credibility of the author or creator of the Web page. The author's credentials, institutional affiliation, educational background, and qualifications for writing on a particular subject should be assessed. Following up on the legitimacy of the page's sponsor can be accomplished if a phone number or postal address is included on the page.

Verifying the accuracy of the information is accomplished by establishing its compatibility with other sources. It is recommended that citations be verified if possible and that even simple things such as spelling, grammatical, and typographical errors should be noted. They may be indicative of a lack of quality in regard to the information itself.

Web sites should include information on when they were created and when they were last updated. This information is used to determine the currency of the information or how up to date it is. Obviously, the purpose of the search and type of information sought influences the 
criticality of this aspect. For the medical information that Patrick needed, currency was essential, whereas for information on topics related to history, it might not be.

In assessing objectivity, the fourth criterion, the challenge is to distinguish fact from opinion or propaganda. The purpose of the Web site and the source of the information are critical in uncovering potential bias. Verifying facts in other sources is also helpful in this regard. Determining if the information is provided as a public service and if it is free of advertising is also critical.

The last criterion suggests that sites should be evaluated regarding coverage. By exploring multiple sources on the same topic, it is possible to identify a variety of viewpoints and to distinguish those sites that cover the topic extensively as opposed to those which provide superficial or minimal information.

It is suggested that examining a site with the five criteria of autbority, accuracy, currency, objectivity, and coverage in mind is a great starting place for determining information quality. Other useful resources that provide greater detail and that are available on the Internet are:

1. An Educator's Guide to Credibility and Web Evaluation Web site for a course on Internet resource evaluation.

\section{bttp://rs.ed.uiuc.edu/wp/credibility}

2. Evaluation Criteria

Evaluation guide in checklist form.

\section{bttp://lib.nmsu.edu/instruction/evalcrit.btml}

3. Web Credibility Project

Research on what leads people to believe what they find on the Web.

\section{bttp://credibility.stanford.edu/}

4. Evaluating Web Resources

Excellent resources for teaching how to evaluate Web sites.

\section{http://www2.widener.edu/Wolfgram-Memorial- Library/webevaluation/webeval.btm}

5. Consumer Health: An Online Manual Specific information regarding points to look at when evaluating health sites.

\section{bttp://nnlm.gov/scr/conblth/evalsite.htm}

\section{Conclusion}

It has been three years since Patrick's surgery for prostate cancer. He is doing well and is confident that he made the right treatment decision for his situation. Patrick also believes that the Internet was his most valuable resource in his quest to "become as knowledgeable as any lay person can be about this." With so much at stake, he was careful to critically evaluate all that he was learning. Unfortunately, that is not the case for many others who are turning to the Internet as a major resource in their self-directed learning. Distinguishing fact from fiction on the Internet is not easy. By increasing awareness of the critical nature of this issue, and by sharing information and resources on the topic, adult education practitioners will be providing an extremely valuable service.

\section{References}

Cahoon, B. (1998). Adult learning and the Internet: Themes and things to come. In B. Cahoon (Ed.), Adult learning and the Internet, (pp. 71-76). New Directions for Adult and Continuing Education, No. 78. San Francisc0: Jossey-Bass.

Gray, D. E. (1999). The Internet in lifelong learning: Liberation or alienation? International Journal of Lifelong Education, 18(2), 119-126.

Internet Detective (2001). An interactive tutorial on evaluating the quality of Internet resources. Retrieved January 14, 2004 from http://www.sosig.ac.uk/ desire/internet-detective.html

Kapoun, J. (1998). Five criteria for evaluating web pages. Retrieved October 15 , 2001, from http://www.library.cornell.edu//okuref/webcrit.html

Kling, R. (1999). Can the "next-generation Internet" effectively support "ordinary citizens"? The Information Society, 15, 57-63.

Knowles, M. S. (1975). Self-directed learning. Chicago: Follett Publishing Company.

Morrison, J. L., \& Stein, L. L. (1999). Assuring integrity of information utility in cyber-learning formats. Reference Review Services, 27(4), 317-326.

net.TUTOR (2001). Evaluation of web sites. Retrieved January 13, 2005, from http://gateway.lib.ohio-state.edu/tutor/

Spear, G. E., \& Mocker, D. W. (1984). The organizing circumstance: Environmental determinants in self-directed learning. Adult Education Quarterly, 43(1), 1-10. 